\title{
Human gut microbiota plays a role in the metabolism of drugs
}

\author{
Lenka Jourova ${ }^{a}$, Pavel Anzenbacher ${ }^{b}$, Eva Anzenbacherova ${ }^{a}$
}

\begin{abstract}
Background and Aims. The gut microbiome, an aggregate genome of trillions of microorganisms residing in the human gastrointestinal tract, is now known to play a critical role in human health and predisposition to disease. It is also involved in the biotransformation of xenobiotics and several recent studies have shown that the gut microbiota can affect the pharmacokinetics of orally taken drugs with implications for their oral bioavailability.

Methods. Review of Pubmed, Web of Science and Science Direct databases for the years 1957-2016.

Results and Conclusions. Recent studies make it clear that the human gut microbiota can play a major role in the metabolism of xenobiotics and, the stability and oral bioavailability of drugs. Over the past 50 years, more than 30 drugs have been identified as a substrate for intestinal bacteria. Questions concerning the impact of the gut microbiota on drug metabolism, remain unanswered or only partially answered, namely (i) what are the molecular mechanisms and which bacterial species are involved? (ii) What is the impact of host genotype and environmental factors on the composition and function of the gut microbiota, (iii) To what extent is the composition of the intestinal microbiome stable, transmissible, and resilient to perturbation? (iv) Has past exposure to a given drug any impact on future microbial response, and, if so, for how long? Answering such questions should be an integral part of pharmaceutical research and personalised health care.
\end{abstract}

Key words: microbiome, metabolism of drugs, gut microbiota, bioavailability, cytochromes P450

Received: April 26, 2016; Accepted: July 13, 2016; Available online: August 2, 2016

http://dx.doi.org/10.5507/bp.2016.039

${ }^{a}$ Department of Medical Chemistry and Biochemistry, Faculty of Medicine and Dentistry and Faculty Hospital Olomouc, Palacky University Olomouc, Czech Republic

${ }^{b}$ Department of Pharmacology, Faculty of Medicine and Dentistry and Faculty Hospital Olomouc, Palacky University Olomouc, Czech Republic

Corresponding author: Eva Anzenbacherova, e-mail:eva.anzenbacherova@upol.cz

\section{INTRODUCTION}

The human body carries trillions of microorganisms, whose aggregate genomes have substantial metabolic potential and are referred to as the microbiome ${ }^{1}$. The largest number of these microorganisms resides in the gut and is termed the gut microbiota. Recent studies have shown that the commensal intestinal flora have profound effects on overall health of the host for which it performs various essential biological functions such as synthesis of vitamins ${ }^{2}$, development and modulation of the immune system, bacterial defense ${ }^{3}$, the intestinal response to epithelial cell injury ${ }^{4}$ and nutrient metabolism ${ }^{5}$. Changes in the structure and diversity of the microbiome are also associated with large array of pathological states such as inflammatory bowel diseases (IBDs) (ref. $\left.{ }^{6}\right)$, metabolic diseases such obesity and diabetes ${ }^{7}$, atherosclerosis ${ }^{8}$ and cardiovascular disease ${ }^{9}$. The gut microbiome is relatively stable but its composition and/or function may be influenced by a range of factors such as $\operatorname{diet}^{10}$, probiotics ${ }^{11}$, and drugs, especially antibiotics ${ }^{12}$. Gut microbiota also affect the metabolism and toxicity of xenobiotics. They express a diverse array of bacterial enzymes which have the ability to metabolize drugs far more extensively than any other part of the body ${ }^{13,14}$. Orally taken drugs reach the gastrointestinal tract and before being absorbed through the epithelial membrane into the blood they are exposed to the intestinal microbiota that may alter their disposition, efficacy and toxicity. Thus, the effect of intestinal microbiota can have significant implication for the oral bioavailability and half-life of drugs ${ }^{15}$. However, understanding of the effect of the intestinal bacteria on the stability of the drugs in the gastrointestinal environment remains limited.

\section{COMPOSITION OF THE GUT MICROBIOTA}

Our understanding of the composition and functions of the human gut microbiota is crucial to assess their metabolic potential and influence on human health. Over the last two decades, knowledge of this area has increased enormously, mainly due to the next-generation sequencing technologies and metabolite profiling. The majority of microbes in our bodies reside in the gastrointestinal tract and provides a wide range of interactions with the host ${ }^{16}$. In addition to bacteria, the gut microbiota consists of archaea, yeasts and filamentous fungi ${ }^{17}$. Recent studies have suggested that the viral component, including a variety of bacteriophages, is also important ${ }^{18}$. Gut microbiota are an extremely diverse bacterial community (approximately 500 species per individual), however, the gastrointestinal tract of a healthy adult is typically represented by two dominant bacterial phyla, the gram-positive Firmicutes and gram-negative Bacteroidetes along with lower abundances 
of Actinobacteria, Proteobacteria and Verrucomicrobia ${ }^{19}$. Bacteroides is the most abundant and the most variable genus $^{20}$. The human gastrointestinal tract is sterile in the prenatal period. During and immediately after birth, initial microbial exposure occurs. While, vaginally delivered infants are colonized by maternal vaginal and faecal microbiota, dominated by Lactobacillus, Prevotella, or Sneathia spp, infants born via caesarean delivery are instead, colonized with microbes associated with the skin, dominated by Staphylococcus, Corynebacterium, and Propionibacterium spp. and with the hospital environment $^{21,22}$. The genus Bifidobacterium, belonging to the phylum Actinobacteria, is a dominant microbial group in healthy breastfed babies. The role of this genus in gut homeostasis is summarized in a published review ${ }^{23}$. Despite great individual variability, the gut microbiome of adults is considered to be relatively stable. According to Arumugan et al., 2011 the human population can be divided into only three enterotypes, identifiable by variation in the levels of one of three genera: Bacteroides (enterotype 1), Prevotella (enterotype 2) and Ruminococcus (enterotype 3) (ref. ${ }^{24}$ ). Also during senescence, the composition of the gut microbiota undergoes new changes. Claesson et al. has found that elderly people differ from the core microbiota and diversity levels of younger adults, with a greater proportion of Bacteroides spp. and distinct abundance patterns of Clostridium groups ${ }^{25}$.

Nevertheless, describing "the normal" gastrointestinal microbiota residing within healthy humans is still very challenging since most are anaerobic and uncultivable and also because of enormous individual differences.

\section{FACTORS INFLUENCING THE COMPOSITION AND FUNCTION OF THE MICROBIOME}

The human gut microbiota is one of the most complex ecosystems on the planet and many studies are focused on the investigation of the composition and function of the gut microbiota and their interaction with the host ${ }^{26,27}$. Imbalance in the composition of this bacterial community can lead to transient intestinal dysfunctions and pathological states ${ }^{28}$. In recent years, an icreasing number of studies on the impact of several classes of drugs, xenobiotics and also dietary plant substances on the composition of the gut microbiota have been published ${ }^{29}$. The microbial intestinal metabolism is adversely affected especially by antibiotics ${ }^{30}$. According to recent studies, antibiotics produce drastic short- and long-term alteration and disruption of the gut microbiota which may lead to the partial decrease in the overall diversity of the microbiome ${ }^{31}$. On the other hand, different studies indicated the plasticity of the gut microbial composition which can be reshaped after discontinuation of antibiotics ${ }^{30,32,33}$.

However, the relationship between the composition of the gut microbiome and host organism is mutual and many recent studies have focused on this unique interaction. To date, a myriad of papers have reported the association of the activity of gut microbiome with obesity and diabetes mellitus ${ }^{7,34,35}$ asthma and allergy ${ }^{36-38}$, aging ${ }^{39,40}$ and even the development and function of the central nervous system $^{41}$, autism and depression ${ }^{42}$.

\section{METABOLISM OF XENOBIOTICS}

With 100 trillion microbes encoding 100-fold more unique genes than our own genome and secreting a diverse array of bacterial enzymes, the gastrointestinal tract has enormous genetic and metabolic potential ${ }^{43}$. The ability of the gut microbiome to metabolize drugs was first recognized over 40 years back $^{44,45}$. To date, dozens drugs and diet-derived bioactive compounds have been reported to undergo direct microbial modification ${ }^{46-49}$, and their number is still growing. In almost all cases, the exact mechanism, the specific reaction and the responsible microbial species remain unknown. However, several mechanisms have been proposed and demonstrated ${ }^{50}$. Currently, new sequencing and pyrotagging technologies allow new insights for answering the questions how gut microbiome affect the disposition, efficacy and toxicity of drugs ${ }^{51}$. Several recent studies have shown that the gut microbiota can influence the pharmacokinetics of orally administered drugs and, thus, may have significant implications for their oral bioavailability ${ }^{52,53}$.

\section{DRUGS METABOLIZED BY THE GUT MICROBIOTA}

\section{Azo reduction}

The first reported example of the azoreduction of drugs by gut microbiota was modification of orally administered prontosil and neoprontosil to sulfanilamide. Concurrently, this conversion was the first known prodrug activation by gut bacteria, as metabolite sulfanilamide was found to have antibacterial effect. Azoreductases produced by the large intestinal microbiota are responsible for the reduction of the azo bond ${ }^{54}$. Prontosil is metabolized to sulfanilamide also in the liver and kidney (Fig. 1.) (ref. $\left.{ }^{55}\right)$. Ginger et al. (1971) has found that antbiotics are able to suppress the conversion of orally administered prontosil to sulfanilamide in the rat. Hence, concomitant intake of prontosil and antibiotics could affect the pharmacokinetics of prontosil and thus its bioavailability. Also, intraperitoneally injected prontosil undergoes gut bacterial metabolism since it can be transported into the gastrointestinal tract by the enterohepatic circulation ${ }^{56}$. Neoprontosil, a high polar antibacterial drug, is also reduced by gut bacterial enzymes to the pharmacologically active metabolite sulfanilamide. However as a high polar drug, neoprontosil is not easily absorbed in the intestine and a large portion is excreted by bile, unchanged ${ }^{56}$.

Sulfasalazine used in the treatment of inflammatory bowel disease belongs also into same group of sulfonamide drugs. In the colon, the azo bond of sulfasalazine is reduced by bacterial azoreductases forming two metabolites - 5-aminosalicylic acid (mesalazine) and sulfapyridine ${ }^{57,58}$. On the other hand, unchanged sulfasalazine was found in the caecum and faeces of antibiotic-treated 


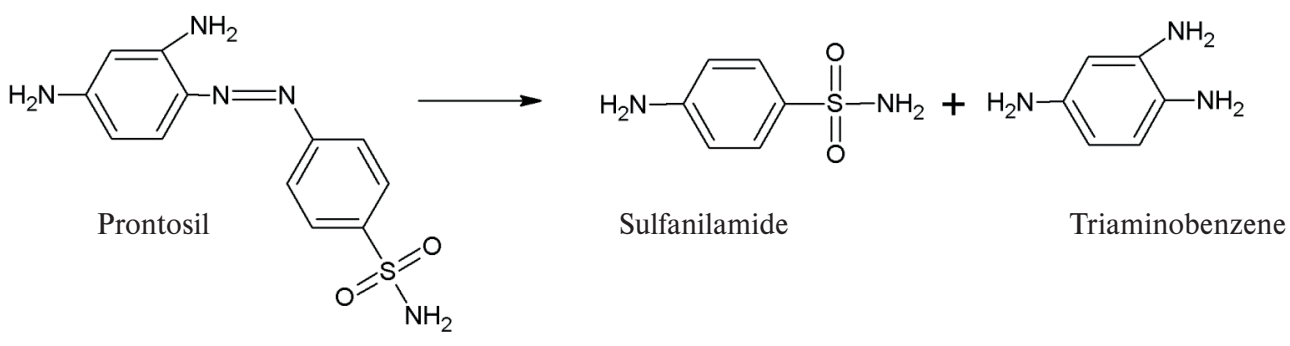

Fig. 1. Azo reduction of prontosil is one example, where intestinal bacteria convert inactive therapeutics into their pharmacologically active form. Bacterial azoreductases present in the distal gut cleave the N-N double bond and produce active metabolite sulfanilamide.

or with germ-free rats. A metabolite of sulfasalazine, sulfapyridine, is absorbed in the colon and could be reason of side effects of sulfasalazine in some patients, such as nausea, skin rash, headache, dizziness and loss of appetite $^{59}$. The synthesis of balsalazide from 4-aminobenzoyl-balanine and salicylic acid was an effort to obviate the side effects of sulfasalazine. Gut microbiota has been shown to metabolize balsalazide to 5-aminosalicylic acid ${ }^{60}$. Another sulfasalazine analog, olsalazine, is converted into two 5-aminosalicylic acid molecules by azoreductase-containing bacteria ${ }^{61}$.

\section{Nitro reduction}

Nitro reductases are the next commonly produced gut bacterial enzymes involved in the metabolism of drugs. Orally administered drugs with a nitro group are reduced to amino products via nitroso and hydroxylamino intermediates $^{62}$. A hypnotic, sedative and anticonvulsant drug of the benzodiazepine class, nitrazepam undergoes nitro reduction catalyzed by the gut bacterial enzymes (Fig. 2) $\left(\right.$ ref. $\left.{ }^{63}\right)$. In this case, the bacterial metabolic activation does not produce pharmacologically active metabolite but products with teratogenic effects. The gastrointestinal tract is the primary side for nitro reduction of nitrazepam to 7-aminonitrazepam, followed by acetylation in the liver to 7-acetylaminonitrazepam, which is teratogenic in rats and mice ${ }^{64}$. This reductive metabolism of nitrazepam occurs with less intensity in rat liver too ${ }^{65}$. Nitro reduction is also involved in the bacterial modification of the next hypnotic, sedative anticonvulsant drug, clonazepam. The
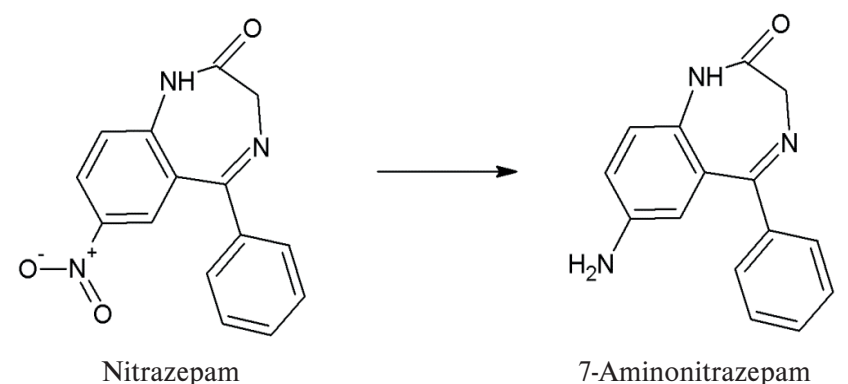

Fig. 2. Nitro reduction of nitrazepam catalyzed by the gut bacterial enzymes produce teratogenic metabolite, 7-Aminonitrazepam. It is an example of clinically undesirable side effect caused by the gut microbiota. participation of the gut microbiota in this metabolism has been demonstrated by studies on germ-free and exgerm-free rats ${ }^{66}$.

Misonidazole is a 2-nitroimidazole derivative, which is an effective radiosensitizer used in radiation therapy to cause normally resistant hypoxic tumor cells to become sensitive to the treatment. The metabolite of nitro reduction, 1-(2-aminoimidazol-1-yl)-3-methoxypropan-2-ol, was found in the excreta of conventional rats in comparison with germ-free rats where the metabolite was not detected. One in vitro study showed that misonidazole is metabolized by gut microbiota into its amino derivative ${ }^{67}$.

\section{Sulfoxide reduction}

Sulfinpyrazone is a uricosuric medication used to treat thromboembolic disorders. In the light of experiments on healthy volunteers and ileostomy patients receiving a single oral dose of sulfinpyrazone, the intestinal microbiota seems to be only site of sulfinpyrazone reduction in $\operatorname{man}^{68}$. The same study also reported the participation of gut microbiota in the formation of sulfinpyrazone in rabbits in vitro and in vivo ${ }^{68}$. Sulindac, also containing the sulfinyl functional group, is a non-steroidal anti-inflammatory drug and is used to treat acute and chronic inflammatory conditions. Strong et al. showed that sulindac is reduced by gut microbiota to sulindac sulfide in man and also in vivo and in vitro in rabbits ${ }^{68}$.

Omeprazole is a derivative of benzimidazole used to treat gastroesophageal reflux disease, peptic ulcer and as a prevention of upper gastrointestinal bleeding. Omeprazole inhibits $\mathrm{H}+/ \mathrm{K}+$-ATPase in the parietal cell, suppressing gastric acid secretion. The pharmacokinetics of omeprazole is influenced by gut bacteria, which reduce omeprazole to sulfide metabolites. This reductive metabolism has only been reported under in vitro conditions. Orally administered omeprazole is well absorbed and does not reach the distal gut. Thus bacterial enzymes are unlikely to be involved in this metabolism ${ }^{69}$.

\section{$\mathrm{N}$-oxide reduction}

Ranitidine and Nizatidine is a histamine $\mathrm{H} 2$ receptor antagonist that inhibits stomach acid production commonly used in the treatment of peptic ulcer and gastroesophageal reflux disease. Using a batch culture fermentation system simulating the colon condition, ranitidine was shown to undergo cleavage on an $\mathrm{N}$-oxide bond causing decreased concentration of the $\operatorname{drug}^{70}$. This 


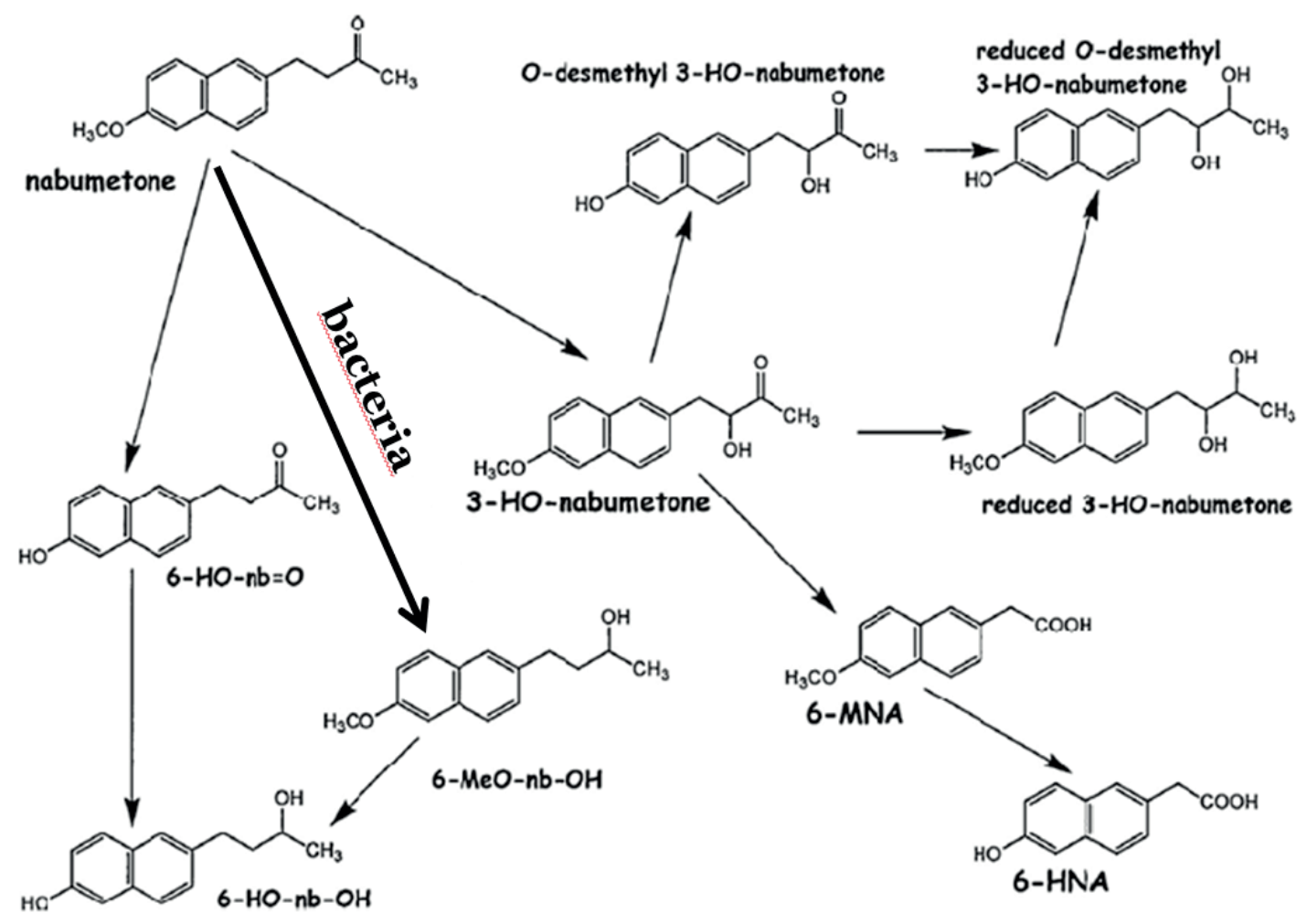

Fig. 3. Metabolism of nabumetone (adapted from Nobilis et al., $2013{ }^{78}$ ). Nabumetone is in vitro reduced by commensal intestinal bacteria into pharmacologically inactive metabolite 4-(6-methoxy-2-naphthyl)-butan-2-ol (reduced nabumetone). These results indicate that gut microbiota may cause lower absorbtion of nabumetone and thus, lower its bioavailability. Metabolites of nabumetone: Nabumetone: 4-(6-methoxy-2-naphthyl)-2-butanone $\left(\mathrm{C}_{15} \mathrm{H}_{16} \mathrm{O}_{2}\right)$; 6-HNA: 6-hydroxy-2-naphthylacetic acid $\left(\mathrm{C}_{12} \mathrm{H}_{10} \mathrm{O}_{3}\right)$; 6-MNA: 6-methoxy-2-naphthylacetic acid $\left(\mathrm{C}_{13} \mathrm{H}_{12} \mathrm{O}_{3}\right)$; 6-HO-nb-OH: 4-(6-hydroxy-2-naphthyl)-butan-2-ol $\left(\mathrm{C}_{14} \mathrm{H}_{16} \mathrm{O}_{2},\right)$; 6-HO-nb=O: 4-(6-hydroxy-2-naphthyl)-butan-2-one $\left(\mathrm{C}_{14} \mathrm{H}_{14} \mathrm{O}_{2}\right)$; 3-HO-nabumetone: 4-(6-methoxy-2-naphthyl)-3-hydroxybutan-2-one $\left(\mathrm{C}_{15} \mathrm{H}_{16} \mathrm{O}_{3}\right)$; 6-MeO-nb-OH: 4-(6-methoxy-2-naphthyl)-butan-2-ol $\left(\mathrm{C}_{15} \mathrm{H}_{18} \mathrm{O}_{2}\right)$; reduced 3-HO-nabumetone: 4-(6-methoxy-2-naphthyl)butan-2,3-diol $\left(\mathrm{C}_{15} \mathrm{H}_{14} \mathrm{O}_{3}\right)$; O-desmethyl 3-OH-nabumetone: 4-(6-hydroxy-2-naphthyl)-3-hydroxybutan-2-one $\left(\mathrm{C}_{14} \mathrm{H}_{14} \mathrm{O}_{3}\right)$; reduced O-desmethyl 3-OH-nabumetone:4-(6-hydroxy-2-naphthyl)-butan-2,3-diol $\left(\mathrm{C}_{14} \mathrm{H}_{12} \mathrm{O}_{3}\right)$.

metabolic modification seems to be partly responsible for the impaired absorption of ranitidine from the colon ${ }^{71}$. In a subsequent study, nizatidine was found to be metabolized via cleavage on an $\mathrm{N}$-oxide bond in the presence of colonic bacteria to hydroxyiminonizatidine, while cimetidine and famotidine did not undergo such bacterial metabolism $^{72}$. Antibiotics such as rifampicin were found to decrease the absorption of ranitidine in the gastrointestinal tract ${ }^{73}$.

\section{Other reductions}

Digoxin is a cardiac glycoside used in the treatment of an atrial fibrillation, atrial flutter and sometimes heart failure that cannot be controlled by other medication. A primary mechanism of action of digoxin is inhibition of the $\mathrm{Na}^{+} / \mathrm{K}^{+}$ATPase, mainly in the myocardium. The absorption and bioavailability of oral digoxin was a topic of much research 40 years ago ${ }^{74}$. In the human body, digoxin may be converted to the inactive metabolites - dihydrodigoxin and dihydrodigoxigenin. These reduced derivatives bind poorly to the $\mathrm{Na}^{+} / \mathrm{K}^{+}$ATPase of cardiac cells and have lower cardiac activity. It has been shown that colonic bacteria are mainly responsible for the formation of these two pharmacologically inactive metabolites ${ }^{75}$.
When the digoxin was given intravenously, the smaller amount of reductive metabolites was found. Lindenbaum et al. (1981) also suggest that the presence of reduced metabolites depends on the individual composition of the intestinal microbiome, since only $10 \%$ of patients on prolonged digoxin treatment excluded reduced derivatives of digoxin. The administration of erythromycin and tetracycline suppresses the reduction of digoxin in vitro and in vivo ${ }^{75}$. Reduction of digoxin to dihydrodigoxin and dihydrodigoxigenin is an example of the pharmacological inactivation of drug by gut microbiota in $\operatorname{man}^{76}$.

Zonisamide is a sulfonamide anticonvulsant used to treat epilepsy. By reduction of the benzisoxazole ring, zonisamide is primarily converted to 2-sulfamoylacetylphenol in vitro. One in vivo experiment on rats showed, that the intestinal microbiota are mainly involved in this modification of zonisamide ${ }^{77}$. Experiments on caecal fluids from rats, mice, hamsters, rabbits, and guineapigs also reported the reductive metabolism forming 2-sulfamoylacetylphenol. In line with these results, one experiment with concomitantly administered antibiotics and zonisamide in rats, showed that the antibiotics significantly inhibited the urinary and faecal excretion of 2-sulfamoylacetylphenol, while re-contamination of the 


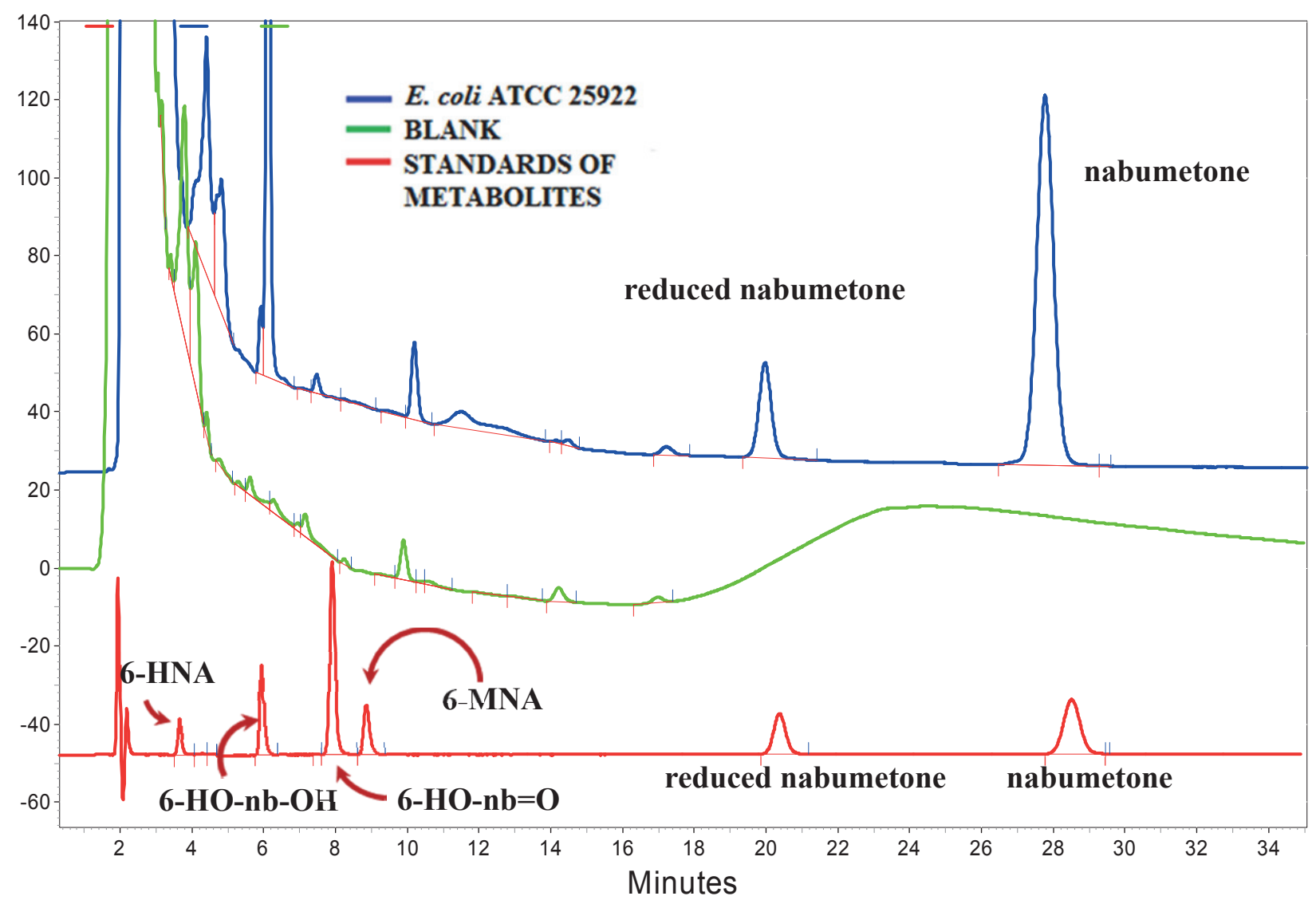

Fig. 4. Chromatographic separation of nabumetone and its metabolites after incubation with the commensal bacteria $E$. coli ATCC 25922.

antibiotic-treated rats with microbiota restored the excretion $^{77}$.

Nabumetone, (4-(6-methoxy-2-naphthyl)-2-butanone), is a widely used as a non-acidic, non-steroidal anti-inflammatory prodrug. After oral administration, nabumetone is converted by oxidative cleavage of its side chain to active metabolite 6-methoxy-2-naphthylacetic acid (6-MNA), a very strong COX-2 inhibitor ${ }^{78}$. Nabumetone is used mainly for the management of pain and inflammation in patients with osteoarthritis and rheumatoid arthritis ${ }^{79}$. The metabolism of nabumetone is well known. Recently, new metabolites of I. phase biotransformation were identified (Fig. 3) $\left(\right.$ ref. $\left.^{78}\right)$. When nabumetone was incubated with live bacterial suspension of commensal E. coli ATCC 25922, a reduced pharmacologically inactive metabolite reduced nabumetone was detected (Fig. 4) (unpublished data). These data suggest that gut bacteria are involved in the metabolism of nabumetone and may cause lower absorbtion of nabumetone and thus, lower bioavailability of the drug. On the basis of these data, a broad spectrum antibiotic, imipenem, was given to rats to evaluate possible effects of antibiotic on the pharmacokinetics of nabumetone. The pharmacokinetics of the main metabolite of nabumetone in the rat plasma, however, was not significantly influenced ${ }^{80}$.

Metronidazole, a 5-nitroimidazole derivative, is used as an antibiotic and antiprotozoal drug. In the liver, metronidazole is metabolized by side-chain oxidation or glucuronidation to form more polar metabolites. Metronidazole can also undergo reductive modification, when enzymes of anaerobic bacteria disrupt the imidazole ring and produce reduced metabolites - $\mathrm{N}$-(2-hydroxyethyl)-oxamic acid and acetamide $^{81}$. Involvement of the gut bacteria in reductive metabolism of metronidazole has been demonstrated in experiments with germ-free rats, since the metabolites $\mathrm{N}$-(2-hydroxyethyl)-oxamic acid and acetamide were only found in excreta of conventional rats and not in the urine or faeces of germ-free rats ${ }^{81,82}$. One, in vitro study with $C$. perfringens or rat caecal contents also confirmed the formation of these metabolites ${ }^{82} \mathrm{~N}$-(2-hydroxyethyl)-oxamic acid and acetamide were detected in small amounts in the urine of patients treated with metronidazole ${ }^{83}$. According to four randomized clinical trials, coadministration of mesazalamine was found to have no effect on the pharmacokinetics of metronidazole ${ }^{84}$.

\section{Hydrolysis}

The metabolism of sorivudine is a good example of the importance of studying the metabolites of orally administered drug and possible changes in their pharmacological activity or even toxicity. The stability of drugs in the intestinal lumen and potential involvement of the gut bacteria on the metabolism should not be overlooked. Sorivudine is a thymine analogue used as an antiviral drug released onto the Japanese market in 1993. The antiviral effect of sorivudine is due to competitive inhibition of viral DNA polymerase. However, eighteen acute deaths of patients were caused by coadministration of sorivudine with oral 
<smiles>[B]/C=C/c1c[nH]c(=O)c(=O)[nH]c1=O</smiles>

Fig. 5. Bacteroidetes $s p$. are responsible for lethal toxicity of sorivudine when concomitantly administered with 5-fluorouracil. Sorivudine metabolite of bacterial metabolism, (E)5-(2-bromovinyl) uracil causes toxic level of anticancer drug 5 -fluorouracil ${ }^{85}$.

5-fluorouracil prodrugs, an anticancer drug. Okuda et al. (1998) investigated the exact mechanism of this toxicity and found that sorivudine metabolite produced by bacterial fermentation was responsible for the lethal effect (Fig. $5)^{85}$. The metabolite (E)-5-(2-bromovinyl) uracil, produced from sorivudine by gut microbiota - mainly Bacteroidetes species, can inhibit the metabolism of 5-fluorouracil and cause toxic levels of the drug ${ }^{86}$. Furtherstudies with germ-free rats indicated that for the formation of (E)-5(2-bromovinyl) uracil, enterobacteria are mainly responsible ${ }^{87}$. Shortly after the deaths of patients, sorivudine was withdrawn from the market.

Lactulose, the keto analogue of lactose (4-( $\beta$-Dgalactopyranosyl)- D-fructose), is a non-absorbable sugar used to treat constipation and hepatic encephalopathy. The enzymes of the intestinal bacteria (Lactobacillus, Bacteroides, E. coli) catalyze the hydrolysis of lactulose into fructose and galactose followed by conversion to lactic and acetic acids, which lower the $\mathrm{pH}$ within the intestine $^{88}$. Lower $\mathrm{pH}$ is favorable for protonization of ammonia and other amines, which can then be eliminated in faeces. This is the mechanism of the laxative effect of lactulose.

\section{Dehydroxylation}

L-DOPA, L-3,4-dihydroxyphenylalanine, is used in the clinical treatment of Parkinson's disease caused by dopamine depletion in the substantia nigra. Orally administered L-dopa undergoes decarboxylation in the central nervous system and increases the level of dopamine. However, the principal site for L-dopa decarboxylation seems to be the gastrointestinal tract ${ }^{89}$. The products of decarboxylation are m-tyramine and m-hydroxyphenylacetic acid, which were detected in the urine of conventional rats but not in pathogen free animals. One study on rat faecal content confirmed the importance of the gut microbiota in the dehydroxylation of the catechol ring of L-dopa and forming the metabolites ${ }^{89}$.

\section{Deacetylation}

Phenacetin was one of the first synthetic antipyretic drugs on the market introduced in 1887 and mainly used as an analgesic. Orally administered phenacetin is rapidly absorbed from the small intestine and metabolized in the liver to paracetamol (acetaminophen). Only a small amount of phenacetin is deacetylated to $p$-phenetidine. This metabolite was detected when rat caecal content were incubated with phenacetin under anaerobic conditions $^{90}$. The formation of $p$-phenetidine is relevant to some clinical complications of phenacetin use, such as methemoglobinemia and nephritis ${ }^{90}$.

\section{Acetylation}

5-aminosalicylic acid (5-ASA, mesalazine), active metabolite of the prodrugs sulfasalazine, balsalazide and olsalazine, is an anti-inflammatory drug used to treat inflammatory bowel disease, such as ulcerative colitis. Small part of orally administered 5-ASA (or its prodrugs) is acetylated by the gut microbiota to $\mathrm{N}$-acetyl-5aminosalicylic acid. In vitro studies have shown that the intestinal bacteria of rats, guinea pigs, dogs and humans are capable of acetylating both 5-ASA and also sulfapyridine $^{91}$. Experiments with faecal suspension of germ-free rats, have shown no acetylating activity. In human faecal suspension, 5-ASA undergoes acetylation under both aerobic and anaerobic conditions as well as by individual bacteria $^{92,93}$.

\section{Thiazole ring opening}

Levamisole, a synthetic imidazothiazole derivative was originally used to treat worm infestations in both humans and animals and the combination with other drugs is used to treat some tumour diseases ${ }^{94}$. Human gut bacteria, mainly Bacteroidetes and Clostridium spp. metabolize levamisole into three metabolites with opened thiazole ring under anaerobic conditions, levametabol-I, levametabolII, and levametabol-III. Co-administered with antibiotics, levamisole has a stronger clinical effect due to inhibition of its bacterial metabolism by intestinal bacteria ${ }^{94}$.

\section{Isoxazole scission}

Risperidone is an antipsychotic medication exhibiting a very potent serotonin receptor - 5-HT antagonism used to treat schizophrenia, bipolar disorder, and irritability in people with autism. Orally administered risperidone is effectively absorbed and its oral bioavailability is approximately $70 \%$ (ref. $^{95}$ ). Gut microbiota of rats converts risperidone into dihydroxy-risperidone and hydroxyl-keto-risperidone under both aerobic and anaerobic conditions $^{96}$. In the liver, antibiotics decrease the bioavailability of risperidone. No gut bioavailability has been reported ${ }^{97}$.

\section{Deamination}

Flucytosine, a fluorinated pyrimidine analogue, is a synthetic antimycotic drug. Vermes et al. found that bacterial enzymes metabolize flucytosine to 5-fluorouracil, since bacterial metabolism was less pronounced in patients treated with antimicrobial agents ${ }^{98}$.

\section{Other reactions}

Lovastatin is a statin drug and potent competitive inhibitor of the enzyme 3-hydroxy-3-methylglutaryl-coenzyme A reductase (a rate limiting enzyme in cholesterol synthesis), used to lower cholesterol levels to reduce risk of cardiovascular disease. Lovastatin is metabolized by human liver to more polar hydroxyl metabolites ${ }^{99}$. It has long been known that lovastatin and related compounds 
Table 1. Summary of drugs metabolized by gut microbiota.

\begin{tabular}{|c|c|c|c|c|c|}
\hline Clinical use & Drug & Influence on drugs & Type of microbial metabolism & $\begin{array}{l}\text { Bacterial } \\
\text { species } \\
\text { involved }\end{array}$ & Ref. \\
\hline \multirow[t]{4}{*}{ Antibiotics } & Prontosil & prodrug activation & Azo reduction & unknown & 55,56 \\
\hline & Neoprontosil & prodrug activation & Azo reduction & unknown & 55,56 \\
\hline & Metronidazole & & Reduction & unknown & 81,82 \\
\hline & Chloramphenicol & increase toxicity & $\begin{array}{l}\text { Amine formation } \\
\text { and hydrolysis }\end{array}$ & unknown & 103 \\
\hline \multirow{7}{*}{$\begin{array}{l}\text { Anti-inflammatory } \\
\text { drugs }\end{array}$} & Sulfasalazine & prodrug activation & Azo reduction & unknown & $57-59$ \\
\hline & Balsalazide & prodrug activation & Azo reduction & unknown & 60 \\
\hline & Olsalazine & prodrug activation & Azo reduction & unknown & 61 \\
\hline & Sulfinpyrazone & increased activity & Sulfoxide reduction & unknown & 68 \\
\hline & Sulindac & increased activity & Sulfoxide reduction & unknown & 68 \\
\hline & Nabumetone & $\begin{array}{l}\text { probably lower } \\
\text { bioavailability }\end{array}$ & Reduction & unknown & 80 \\
\hline & Mesalazine & & Acetylation & unknown & $91-93$ \\
\hline \multirow[t]{2}{*}{ Analgesics } & Acetaminophen & increased toxicity & $\begin{array}{l}\text { O-sulfation; C-S cleavage of } \\
\text { acetaminophen-3-cysteine }\end{array}$ & $\begin{array}{l}\text { Clostridium } \\
\text { difficile }\end{array}$ & 106 \\
\hline & Phenacetin & decreased activity & Deacetylation & unknown & 90 \\
\hline Cardiotonics & Digoxin & decreased cardiac activity & Reduction & $\begin{array}{l}\text { Eggerthella } \\
\text { lenta }\end{array}$ & 75,76 \\
\hline \multirow[t]{3}{*}{ Anti-psychotics } & Risperidone & $\begin{array}{l}\text { inducting symptoms of } \\
\text { Parkinson's disease }\end{array}$ & $\begin{array}{l}\text { Isoxazole scission } \\
\text { or hydroxylation }\end{array}$ & unknown & 96 \\
\hline & L-Dopa & decreased activity & Dehydroxylation & unknown & 89 \\
\hline & Zonisamide & affect reduction & Reduction & unknown & 77 \\
\hline Antivirotics & Sorivudine & $\begin{array}{l}\text { its microbial metabolite } \\
\text { can cause lethal toxicity of } \\
\text { 5-fluorouracil when } \\
\text { co-administered with it. }\end{array}$ & Hydrolysis & Bacteroides & 87,85 \\
\hline Antifungals & Flucytosine & increased activity or toxicity & Deamination & unknown & 98 \\
\hline Hypolipidemics & Lovastatine & altered pharmacokinetics & Hydrolysis & unknown & $\begin{array}{l}52 \\
100- \\
102\end{array}$ \\
\hline Hypnotics & Nitrazepam & inducing teratogenicity & Nitro reduction & $\begin{array}{l}\text { Clostridium } \\
\text { leptum }\end{array}$ & $63-65$ \\
\hline Antiepileptics & Clonazepam & & Nitro reduction & unknown & 66 \\
\hline Cytostatics & Misonidazole & & Nitro reduction & unknown & 67 \\
\hline \multirow[t]{3}{*}{ Antiulcerotics } & Omeprazole & forming sulfide metabolites & Sulfoxide reduction & unknown & 69 \\
\hline & Ranitidine & decreased intestinal & N-oxide reduction & unknown & 70 \\
\hline & Nizatidine & $\begin{array}{l}\text { absorption and systemic } \\
\text { bioavailability }\end{array}$ & $\mathrm{N}$-oxide reduction & & 72 \\
\hline Anthelmintics & Levamisole & increased activity & Thiazole ring opening & $\begin{array}{l}\text { Bacteroides } \\
\text { and } \\
\text { Clostridium } \\
\text { spp. }\end{array}$ & 94 \\
\hline Prebiotics & Lactulose & $\begin{array}{l}\text { stimulating the growth of } \\
\text { beneficial bacteria }\end{array}$ & Hydrolysis & unknown & 88 \\
\hline
\end{tabular}

can be metabolized by the gut microbiota to a phosphorylated derivative and a number of hydroxylated microbial metabolites ${ }^{100-102}$. Lovastatin is a lactone prodrug that is readily hydrolyzed in vivo to form the pharmacologically active 2-hydroxy lovastatic acid. The involvement of gut microbiota in the metabolism of lovastatin to its bioac- tive metabolite was demonstrated in vitro and in vivo in experiments with rats. Administration of antibiotics has been shown to reduce the bacterial metabolism of lovastatin in the intestine and thus, decreases the bioavailability of the active metabolite, mainly due to antibiotic-mediated inhibition of intestinal bacteria ${ }^{52}$. 
Chloramphenicol is an antibiotic with a broad spectrum activity used to treat a number of bacterial infections. Chloramphenicol contains an amide of dichloroacetic acid and a nitrobenzene group which undergoes bacterial metabolism in the gastrointestinal tract. Incubation of chloramphenicol with bacteria commonly found in human faeces has shown that the gut microbiota is able to metabolite chloramphenicol into a several metabolites, including the toxic metabolite p-aminophenyl-2-amin-1,3propanediol related to risk of marrow aplasia ${ }^{103}$. Marrow aplasia has been shown only in a few percent of patients given chloramphenicol orally and microbiota contained a large amount of coliform microorganisms capable of producing toxic metabolites of chloramphenicol ${ }^{103}$.

Acetaminophen ( $N$-acetyl- $p$-aminophenol, paracetamol) is one of the most widely used nonprescription medicines in the world for its analgesic and antipyretic properties. The biotransformation and potential toxicity of acetaminophen have been intensively studied and the fate of this drug in the human body is be well known ${ }^{104,105}$. Orally prescribed acetaminophen is mostly modified into two pharmacologically inactive metabolites, glucuronide and sulfate. A minor fraction is oxidized primarily by cytochromes P450 into a reactive metabolite NAPQI (5$10 \%)$, which is responsible for acetaminophen induced toxicity. NAPQI is detoxified by binding with glutathione to form acetaminophen glutathione conjugate, which is ultimately eliminated by the urine. The liver, and to a lesser extent the kidney are the major organs involved in the metabolism of acetaminophen but intestinal bacteria are also engaged, since two microbial cometabolites $p$-cresol sulfate and phenylacetylglutamine have been found. The microbial metabolite $p$-cresol undergoes o-sulfonation to produce the $p$-cresol sulfate and competes for the binding site of sulfotransferases with acetaminophen leading to increased acetaminophen toxicity ${ }^{106}$. In the light of these results, the role of the gut microbiota in the metabolism of drugs and the microbiome profile/composition of an individual should be taken into consideration, even with the conventionally used drugs with very well studied metabolism such as acetaminophen.

The list of all described drugs is summarized in Table 1.

\section{CONCLUSION}

On the basis of recent studies, the human gut microbiota can play a major role in the metabolism of xenobiotics and affect the stability and oral bioavailability of drugs. In the last 50 years, more than 30 drugs have been identified as a substrate for intestinal bacteria. Many questions concerning the impact of the gut microbiota on drug metabolism, however, remain unanswered or answered only partially, namely (i) what are the molecular mechanisms and which bacterial species are involved? what is the impact of host genotype and environmental factors on the composition and function of the gut microbiota, (iii) to what extent is the composition of the intestinal microbiome stable, transmissible, and resilient to perturba- tion? (iv) Has a past exposure to a given drug any impact on future microbial response, and, if so for how long? Answering such questions should be an integral part of pharmaceutical research and personalised health care.

Acknowledgment: This work was supported by the Czech Science Foundation (grant no. P303/12/0535), by the internal student's grant of the Palacky University (LF_2016_012) and by the Ministry of Health, Czech republic - conceptual development of research organization (FNO1, 00098892).

Author contributions: LJ: manuscript writing; PA, EA: critical review of the manuscript.

Conflict of interest statement: The authors declare there are no conflicts of interest regarding the publication of this article.

\section{REFERENCES}

1. Turnbaugh PJ, Stintzi A. Human health and disease in a microbial world. Front Microbiol 2011;2.

2. Hill MJ. Intestinal flora and endogenous vitamin synthesis. Eur J Cancer Prev 1997;6 Suppl 1:S43-5.

3. Viggiano D, laniro G, Vanella G, Bibbo S, Bruno G, Simeone G, Mele G. Gut barrier in health and disease: focus on childhood. Eur Rev Med Pharmacol Sci 2015;19(6):1077-85.

4. Zhan Y, Chen PJ, Sadler WD, Wang F, Poe S, Nunez G, Eaton KA, Chen GY. Gut microbiota protects against gastrointestinal tumorigenesis caused by epithelial injury. Cancer Res 2013;73(24):7199-210.

5. Macfarlane S, Macfarlane GT. Regulation of short-chain fatty acid production. Proc Nutr Soc 2003;62(1):67-72.

6. Ferreira CM, Vieira AT, Vinolo MA, Oliveira FA, Curi R, Martins Fdos $\mathrm{S}$. The central role of the gut microbiota in chronic inflammatory diseases. J Immunol Res 2014;2014:689492.

7. Forslund K, Hildebrand F, Nielsen T, Falony G, Le Chatelier E, Sunagawa S, Prifti E, Vieira-Silva S, Gudmundsdottir V, Krogh Pedersen $H$, Arumugam M, Kristiansen $K$, Voigt AY, Vestergaard $H$, Hercog R, Igor Costea P, Kultima JR, Li J, Jorgensen T, Levenez F, Dore J, Nielsen HB, Brunak S, Raes J, Hansen T, Wang J, Ehrlich SD, Bork P, Pedersen O. Disentangling type 2 diabetes and metformin treatment signatures in the human gut microbiota. Nature 2015;528(7581):2626.

8. Koeth RA, Wang Z, Levison BS, Buffa JA, Org E, Sheehy BT, Britt EB, Fu X, Wu Y, Li L, Smith JD, DiDonato JA, Chen J, Li H, Wu GD, Lewis JD, Warrier M, Brown JM, Krauss RM, Tang WHW, Bushman FD, Lusis AJ, Hazen SL. Intestinal microbiota metabolism of I-carnitine, a nutrient in red meat, promotes atherosclerosis. Nat Med 2013;19(5):576-85.

9. Singh V, Yeoh BS, Vijay-Kumar M. Gut microbiome as a novel cardiovascular therapeutic target. Current Opinion in Pharmacology 2016;27:8-12.

10. Scott KP, Gratz SW, Sheridan PO, Flint HJ, Duncan SH. The influence of diet on the gut microbiota. Pharmacol Res 2013;69(1):52-60.

11. Stojančević $M$, Bojić $G, A l-S a l a m i ~ H$, Mikov M. The influence of intestinal tract and probiotics on the fate of orally administered drugs. Curr Issues Mol Biol 2013;4(16):2.

12. Maurice CF, Haiser HJ, Turnbaugh PJ. Xenobiotics shape the physiology and gene expression of the active human gut microbiome. Cell 2013;152(1):39-50.

13. Shamat MA. The role of the gastrointestinal microflora in the metabolism of drugs. International journal of pharmaceutics 1993;97(1):113.

14. Mikov M. The metabolism of drugs by the gut flora. European journal of drug metabolism and pharmacokinetics 1994;19(3):201-07.

15. Al-Hilal TA, Alam F, Byun Y. Oral drug delivery systems using chemical conjugates or physical complexes. Adv Drug Deliv Rev 2013;65(6):845-64.

16. Consortium HMP. Structure, function and diversity of the healthy human microbiome. Nature 2012;486(7402):207-14. 
17. Miller TL, Wolin M. Methanogens in human and animal intestinal tracts. Systematic and applied microbiology 1986;7(2):223-29.

18. Zhang T, Breitbart M, Lee WH, Run JQ, Wei CL, Soh SW, Hibberd ML, Liu ET, Rohwer F, Ruan Y. RNA viral community in human feces: prevalence of plant pathogenic viruses. PLoS Biol 2006;4(1):e3.

19. Bäckhed F, Ley RE, Sonnenburg JL, Peterson DA, Gordon J. Host-bacterial mutualism in the human intestine. science 2005;307(5717):1915-20.

20. Tap J, Mondot S, Levenez F, Pelletier E, Caron C, Furet JP, Ugarte E, Muñoz-Tamayo R, Paslier DL, Nalin R. Towards the human intestinal microbiota phylogenetic core. Environmental microbiology 2009;11(10):2574-84.

21. Rodríguez JM, Murphy K, Stanton C, Ross RP, Kober Ol, Juge N Avershina E, Rudi K, Narbad A, Jenmalm MC. The composition of the gut microbiota throughout life, with an emphasis on early life. Microbial ecology in health and disease 2015;26.

22. Biasucci G, Rubini M, Riboni S, Morelli L, Bessi E, Retetangos C. Mode of delivery affects the bacterial community in the newborn gut. Early Human Development 2010;86(1, Supplement):13-15.

23. Tojo R, Suarez A, Clemente MG, de los Reyes-Gavilan CG, Margolles A, Gueimonde M, Ruas-Madiedo P. Intestinal microbiota in health and disease: role of bifidobacteria in gut homeostasis. World J Gastroenterol 2014;20(41):15163-76.

24. Arumugam $M$, Raes J, Pelletier E, Le Paslier D, Yamada T, Mende DR, Fernandes GR, Tap J, Bruls T, Batto J-M, Bertalan M, Borruel N, Casellas F, Fernandez L, Gautier L, Hansen T, Hattori M, Hayashi T, Kleerebezem M, Kurokawa K, Leclerc M, Levenez F, Manichanh C, Nielsen HB, Nielsen T, Pons N, Poulain J, Qin J, Sicheritz-Ponten T, Tims S, Torrents D, Ugarte E, Zoetendal EG, Wang J, Guarner F Pedersen O, de Vos WM, Brunak S, Dore J, Weissenbach J, Ehrlich $\mathrm{SD}$, Bork P. Enterotypes of the human gut microbiome. Nature 2011;473(7346):174-80.

25. Claesson MJ, Cusack S, O'Sullivan O, Greene-Diniz R, de Weerd H, Flannery E, Marchesi JR, Falush D, Dinan T, Fitzgerald G. Composition, variability, and temporal stability of the intestinal microbiota of the elderly. Proceedings of the National Academy of Sciences 2011;108(Supplement 1):4586-91.

26. Dethlefsen L, Relman DA. Incomplete recovery and individualized responses of the human distal gut microbiota to repeated antibiotic perturbation. Proceedings of the National Academy of Sciences 2011;108(Supplement 1):4554-61.

27. Claesson MJ, Jeffery IB, Conde S, Power SE, O'Connor EM, Cusack S, Harris HM, Coakley M, Lakshminarayanan B, O'Sullivan O. Gut microbiota composition correlates with diet and health in the elderly. Nature 2012:488(7410):178-84

28. Manichanh C, Reeder J, Gibert P, Varela E, Llopis M, Antolin M Guigo R, Knight R, Guarner F. Reshaping the gut microbiome with bacterial transplantation and antibiotic intake. Genome research 2010;20(10):1411-19.

29. Shashkova T, Popenko A, Tyakht A, Peskov K, Kosinsky Y, Bogolubsky L, Raigorodskii A, Ischenko D, Alexeev D, Govorun V. Agent Based Modeling of Human Gut Microbiome Interactions and Perturbations. PLoS ONE 2016;11(2):e0148386.

30. Pérez-Cobas AE, Gosalbes MJ, Friedrichs A, Knecht $H$, Artacho A, Eismann K, Otto W, Rojo D, Bargiela R, von Bergen M. Gut microbiota disturbance during antibiotic therapy: a multi-omic approach. Gut 2013;62(11):1591-601.

31. Jernberg C, Löfmark S, Edlund C, Jansson JK. Long-term ecological impacts of antibiotic administration on the human intestinal microbiota. The ISME journal 2007;1(1):56-66.

32. Dethlefsen L, Relman DA. Incomplete recovery and individualized responses of the human distal gut microbiota to repeated antibiotic perturbation. Proc Natl Acad Sci U S A 2011;108 Suppl 1:4554-61.

33. De La Cochetiere MF, Durand T, Lepage P, Bourreille A, Galmiche JP, Dore J. Resilience of the dominant human fecal microbiota upon short-course antibiotic challenge. J Clin Microbiol 2005;43(11):558892

34. Knip $M$, Siljander $H$. The role of the intestinal microbiota in type diabetes mellitus. Nat Rev Endocrinol 2016;12(3):154-67.

35. Ley RE, Backhed F, Turnbaugh P, Lozupone CA, Knight RD, Gordon Jl. Obesity alters gut microbial ecology. Proc Natl Acad Sci U S A 2005; 102(31):11070-5

36. Panzer AR, Lynch SV. Influence and effect of the human microbiome in allergy and asthma. Curr Opin Rheumatol 2015;27(4):373-80.
37. Huang YJ, Boushey HA. The microbiome in asthma. J Allergy Clin Immunol 2015;135(1):25-30.

38. Legatzki A, Rosler B, von Mutius E. Microbiome diversity and asthma and allergy risk. Curr Allergy Asthma Rep 2014;14(10):466.

39. O'Toole PW, Jeffery IB. Gut microbiota and aging. Science 2015:350(6265):1214-5

40. Zapata HJ, Quagliarello VJ. The microbiota and microbiome in aging: potential implications in health and age-related diseases. J Am Geriatr Soc 2015;63(4):776-81.

41. Kelly JR, Clarke G, Cryan JF, Dinan TG. Brain-gut-microbiota axis: challenges for translation in psychiatry. Ann Epidemiol 2016.

42. Mangiola F, laniro G, Franceschi F, Fagiuoli S, Gasbarrini G, Gasbarrini A. Gut microbiota in autism and mood disorders. World J Gastroenterol 2016;22(1):361-8.

43. Qin J, Li R, Raes J, Arumugam M, Burgdorf KS, Manichanh C, Nielsen T, Pons N, Levenez F, Yamada T, Mende DR, Li J, Xu J, Li S, Li D, Cao J, Wang B, Liang H, Zheng H, Xie Y, Tap J, Lepage P, Bertalan M, Batto J-M, Hansen T, Le Paslier D, Linneberg A, Nielsen HB, Pelletier E, Renault P, Sicheritz-Ponten T, Turner K, Zhu H, Yu C, Li S, Jian M, Zhou Y, Li Y, Zhang X, Li S, Qin N, Yang H, Wang J, Brunak S, Dore J, Guarner F, Kristiansen K, Pedersen O, Parkhill J, Weissenbach J, Bork P, Ehrlich $\mathrm{SD}$, Wang J. A human gut microbial gene catalogue established by metagenomic sequencing. Nature 2010;464(7285):59-65.

44. Scheline RR. Drug metabolism by intestinal microorganisms. J Pharm Sci 1968;57(12):2021-37.

45. Scheline RR. Metabolism of foreign compounds by gastrointestinal microorganisms. Pharmacol Rev 1973;25(4):451-523.

46. Sousa T, Paterson R, Moore V, Carlsson A, Abrahamsson B, Basit AW. The gastrointestinal microbiota as a site for the biotransformation of drugs. Int J Pharm 2008;363(1):1-25.

47. Saad R, Rizkallah MR, Aziz RK. Gut Pharmacomicrobiomics: the tip of an iceberg of complex interactions between drugs and gut-associated microbes. Gut Pathogens 2012;4(1):1-13.

48. $\mathrm{Li} \mathrm{H}, \mathrm{He} \mathrm{J}$, Jia W. The influence of gut microbiota on drug metabolism and toxicity. Expert Opin Drug Metab Toxicol 2016;12(1):31-40.

49. Kang MJ, Kim HG, Kim JS, Oh do G, Um YJ, Seo CS, Han JW, Cho HJ, Kim GH, Jeong TC, Jeong HG. The effect of gut microbiota on drug metabolism. Expert Opin Drug Metab Toxicol 2013;9(10):1295-308.

50. Sousa T, Paterson R, Moore V, Carlsson A, Abrahamsson B, Basit AW. The gastrointestinal microbiota as a site for the biotransformation of drugs. Int J Pharm 2008:363.

51. Saad R, Rizkallah MR, Aziz RK. Gut Pharmacomicrobiomics: the tip of an iceberg of complex interactions between drugs and gut-associated microbes. Gut Pathog 2012;4(1):16.

52. Yoo DH, Kim IS, Van Le TK, Jung IH, Yoo HH, Kim DH. Gut microbiotamediated drug interactions between lovastatin and antibiotics. Drug Metab Dispos 2014;42(9):1508-13.

53. Yoo HH, Kim IS, Yoo DH, Kim DH. Effects of orally administered antibiotics on the bioavailability of amlodipine: gut microbiota-mediated drug interaction. J Hypertens 2016;34(1):156-62.

54. Fuller AT. Is p-aminobenzenesulphonamide the active agent in prontosil therapy? Lancet 1937;1:194-98.

55. Fouts JR, Kamm JJ, Brodie BB. Enzymatic reduction of prontosil and other azo dyes. J Pharmacol Exp Ther 1957;120(3):291-300.

56. Gingell R, Bridges JW, Williams RT. The Role of the Gut Flora in the Metabolism of Prontosil and Neoprontosil in the Rat. Xenobiotica 1971;1(2):143-56.

57. Das KM, Eastwood MA, McManus JPA, Sircus W. The metabolism of salicylazosulphapyridine in ulcerative colitis: I The relationship between metabolites and the response to treatment in inpatients. Gut 1973;14(8):631-36.

58. Peppercorn MA, Goldman P. The role of intestinal bacteria in the metabolism of salicylazosulfapyridine. J Pharmacol Exp Ther 1972;181(3):555-62.

59. Peppercorn MA, Goldman P. Distribution studies of salicylazosulfapyridine and its metabolites. Gastroenterology 1973;64(2):240-5.

60. Chan RP, Pope DJ, Gilbert AP, Sacra PJ, Baron JH, Lennard-Jones JE. Studies of two novel sulfasalazine analogs, ipsalazide and balsalazide. Dig Dis Sci 1983;28(7):609-15.

61. Wadworth AN, Fitton A. Olsalazine. A review of its pharmacodynamic and pharmacokinetic properties, and therapeutic potential in inflammatory bowel disease. Drugs 1991;41(4):647-64.

62. Nambara S, Yamaha T. [Comparison of bacterial and microsoma azo- and nitro-reductases (author's transl)]. Yakugaku Zasshi 1975;95(11):1302-6. 
63. Takeno S, Sakai T. Involvement of the intestinal microflora in nitrazepam-induced teratogenicity in rats and its relationship to nitroreduction. Teratology 1991;44(2):209-14.

64. Takeno S, Hirano Y, Kitamura A, Sakai T. Comparative developmental toxicity and metabolism of nitrazepam in rats and mice. Toxicology and applied pharmacology 1993;121(2):233-38.

65. Rafii F, Sutherland JB, Hansen EB, Jr., Cerniglia CE. Reduction of nitrazepam by Clostridium leptum, a nitroreductase-producing bacterium isolated from the human intestinal tract. Clin Infect Dis 1997;25 Suppl 2:S121-2.

66. Elmer GW, Remmel RP. Role of the intestinal microflora in clonazepam metabolism in the rat. Xenobiotica 1984;14(11):829-40.

67. Koch RL, Beaulieu BB, Jr., Goldman P. Role of the intestinal flora in the metabolism of misonidazole. Biochem Pharmacol 1980;29(24):3281-4.

68. Strong HA, Renwick AG, George CF, Liu YF, Hill MJ. The reduction of sulphinpyrazone and sulindac by intestinal bacteria. Xenobiotica 1987; 17(6):685-96

69. Watanabe K, Yamashita S, Furuno K, Kawasaki H, Gomita Y Metabolism of omeprazole by gut flora in rats. J Pharm Sci 1995;84(4):516-7.

70. Basit AW, Lacey LF. Colonic metabolism of ranitidine: implications for its delivery and absorption. Int J Pharm 2001;227(1-2):157-65.

71. Basit AW, Podczeck F, Newton JM, Waddington WA, Ell PJ, Lacey LF. The use of formulation technology to assess regional gastrointestinal drug absorption in humans. Eur J Pharm Sci 2004;21(2-3):179-89.

72. Basit AW, Newton JM, Lacey LF. Susceptibility of the H2-receptor antagonists cimetidine, famotidine and nizatidine, to metabolism by the gastrointestinal microflora. Int J Pharm 2002;237(1-2):23-33.

73. Machavaram KK, Gundu J, Yamsani MR. Effect of ketoconazole and rifampicin on the pharmacokinetics of ranitidine in healthy human volunteers: a possible role of P-glycoprotein. Drug Metabol Drug Interact 2006;22(1):47-65.

74. Greenblatt DJ, Smith TW, Koch-Weser J. Bioavailability of drugs: the digoxin dilemma. Clin Pharmacokinet 1976;1(1):36-51.

75. Lindenbaum J, Rund DG, Butler VP, Jr., Tse-Eng D, Saha JR. Inactivation of digoxin by the gut flora: reversal by antibiotic therapy. $\mathrm{N}$ Engl J Med 1981;305(14):789-94.

76. Magnusson JO, Bergdahl B, Bogentoft C, Jonsson UE. Metabolism of digoxin and absorption site. Br J Clin Pharmacol 1982;14(2):284-5.

77. Kitamura S, Sugihara K, Kuwasako M, Tatsumi K. The role of mammalian intestinal bacteria in the reductive metabolism of zonisamide. $J$ Pharm Pharmacol 1997;49(3):253-6.

78. Nobilis M, Mikusek J, Szotakova B, Jirasko R, Holcapek M Chamseddin C, Jira T, Kucera R, Kunes J, Pour M. Analytical power of LLE-HPLC-PDA-MS/MS in drug metabolism studies: identification of new nabumetone metabolites. J Pharm Biomed Anal 2013;80:164 72.

79. Hedner T, Samulesson O, Wahrborg P, Wadenvik H, Ung KA, Ekbom A Nabumetone: therapeutic use and safety profile in the management of osteoarthritis and rheumatoid arthritis. Drugs 2004;64(20):231543; discussion 44-5.

80. Jourova L AP, Matuskova Z, Nobilis M, Vecera R, Tlaskalova-Hogenova $\mathrm{H}$, Kverka M, Kolar M, Anzenbacherova E. Imipenem, a carbapenem type antibiotic, does not alter pharmacokinetics of a model drug nabumetone. Toxicol Lett 2015;238:S332.

81. Koch RL, Goldman P. The anaerobic metabolism of metronidazole forms N-(2-hydroxyethyl)-oxamic acid. J Pharmacol Exp Ther 1979;208(3):406-10.

82. Koch RL, Chrystal EJ, Beaulieu BB, Jr., Goldman P. Acetamide--a metabolite of metronidazole formed by the intestinal flora. Biochem Pharmacol 1979;28(24):3611-5.

83. Kock RL, Beaulieu BB, Jr., Chrystal EJ, Goldman P. A metronidazole metabolite in human urine and its risk. Science 1981;211(4480):398400.

84. Pierce D, Corcoran M, Martin P, Barrett $K$, Inglis S, Preston $P$, Thompson TN, Willsie SK. Effect of MMX(R) mesalamine coadministration on the pharmacokinetics of amoxicillin, ciprofloxacin XR, metronidazole, and sulfamethoxazole: results from four randomized clinical trials. Drug Des Devel Ther 2014;8:529-43.

85. Okuda H, Ogura K, Kato A, Takubo H, Watabe T. A possible mechanism of eighteen patient deaths caused by interactions of sorivudine, a new antiviral drug, with oral 5-fluorouracil prodrugs. J Pharmacol Exp Ther 1998;287(2):791-9.
86. Nakayama H, Kinouchi T, Kataoka K, Akimoto S, Matsuda Y, Ohnishi Y. Intestinal anaerobic bacteria hydrolyse sorivudine, producing the high blood concentration of 5-(E)-(2-bromovinyl)uracil that increases the level and toxicity of 5 -fluorouracil. Pharmacogenetics 1997;7(1):35-43.

87. Ashida N, ljichi K, Watanabe Y, Machida H. Metabolism of 5'-ether prodrugs of 1-beta-D-arabinofuranosyl-E-5-(2-bromovinyl)uracil in rats. Biochem Pharmacol 1993;46(12):2201-7.

88. Elkington SG, Floch MH, Conn HO. Lactulose in the Treatment of Chronic Portal-Systemic Encephalopathy. New England Journal of Medicine 1969;281(8):408-12.

89. Goldin BR, Peppercorn MA, Goldman P. Contributions of host and intestinal microflora in the metabolism of L-dopa by the rat. $J$ Pharmacol Exp Ther 1973;186(1):160-6.

90. Smith G, Griffiths L. Metabolism of N-acylated and O-alkylated drugs by the intestinal microflora during anaerobic incubation in vitro. Xenobiotica 1974;4(8):477-87.

91. Dull BJ, Salata K, Goldman P. Role of the intestinal flora in the acetylation of sulfasalazine metabolites. Biochem Pharmacol 1987;36(21):3772-4.

92. van Hogezand RA, Kennis HM, van Schaik A, Koopman JP, van Hees $\mathrm{PA}$, van Tongeren JH. Bacterial acetylation of 5-aminosalicylic acid in faecal suspensions cultured under aerobic and anaerobic conditions. Eur J Clin Pharmacol 1992;43(2):189-92.

93. Delomenie C, Fouix S, Longuemaux S, Brahimi N, Bizet C, Picard B, Denamur E, Dupret JM. Identification and functional characterization of arylamine $\mathrm{N}$-acetyltransferases in eubacteria: evidence for highly selective acetylation of 5-aminosalicylic acid. J Bacteriol 2001;183(11):3417-27.

94. Shu YZ, Kingston DG, Van Tassell RL, Wilkins TD. Metabolism of levamisole, an anti-colon cancer drug, by human intestinal bacteria. Xenobiotica 1991;21(6):737-50.

95. He H, Richardson JS. A pharmacological, pharmacokinetic and clinical overview of risperidone, a new antipsychotic that blocks serotonin 5-HT2 and dopamine D2 receptors. Int Clin Psychopharmacol 1995;10(1):19-30.

96. Meuldermans W, Hendrickx J, Mannens G, Lavrijsen K, Janssen C, Bracke J, Le Jeune L, Lauwers W, Heykants J. The metabolism and excretion of risperidone after oral administration in rats and dogs. Drug Metab Dispos 1994;22(1):129-38.

97. Baciewicz AM, Chrisman CR, Finch CK, SelfTH. Update on rifampin, rifabutin, and rifapentine drug interactions. Curr Med Res Opin 2013;29(1):1-12

98. Vermes A, Kuijper EJ, Guchelaar HJ, Dankert J. An in vitro study on the active conversion of flucytosine to fluorouracil by microorganisms in the human intestinal microflora. Chemotherapy 2003;49(12):17-23.

99. Greenspan MD, Yudkovitz JB, Alberts AW, Argenbright LS, Arison $\mathrm{BH}$, Smith JL. Metabolism of lovastatin by rat and human liver microsomes in vitro. Drug Metab Dispos 1988;16(5):678-82.

100. Endo A, Yamashita H, Naoki H, Iwashita T, Mizukawa Y. Microbial phosphorylation of compactin (ML-236B) and related compounds. J Antibiot (Tokyo) 1985;38(3):328-32.

101. Serizawa N, Nakagawa K, Tsujita Y, Terahara A, Kuwano H, Tanaka M 6 alpha-Hydroxy-iso-ML-236B ( 6 alpha-hydroxy-iso-compactin) and ML-236A, microbial transformation products of ML-236B. J Antibiot (Tokyo) 1983;36(7):918-20.

102. Serizawa N, Nakagawa K, Tsujita Y, Terahara A, Kuwano H. 3 alphaHydroxy-ML-236B (3 alpha-hydroxycompactin), microbial transformation product of ML-236B (compactin). J Antibiot (Tokyo) 1983;36(5):608-10.

103. Holt R. The bacterial degradation of chloramphenicol. Lancet 1967; 1(7502):1259-60.

104. Prescott LF. Kinetics and metabolism of paracetamol and phenacetin. Br J Clin Pharmacol 1980;10 Suppl 2:291S-98S.

105. Lau GS, Critchley JA. The estimation of paracetamol and its major metabolites in both plasma and urine by a single high-performance liquid chromatography assay. J Pharm Biomed Anal 1994;12(12):1563-72.

106. Clayton TA, Baker D, Lindon JC, Everett JR, Nicholson JK. Pharmacometabonomic identification of a significant host-microbiome metabolic interaction affecting human drug metabolism. Proc Natl Acad Sci U S A 2009;106(34):14728-33. 